\title{
The Energy Processing by Power Electronics and its Impact on Power Quality
}

\author{
J. E. Rocha and W. D. C. Sanchez*
}

Department of Electrical Engineering, Federal University of Technology - Paraná, BRAZIL

\section{Article history:}

Received Sep 19, 2012

Received in revised form Sep 24, 2012 Accepted Sep 30, 2012 Available online

\begin{abstract}
This paper discusses the electrical architectures adopted in wind turbines and its impact on the harmonic flux at the connected electric network. The integration of wind electric generators with the power grid needs energy processing by power electronics. It shows that different types of wind turbine generator systems use different types of electronic converters. This work provides a discussion on harmonic distortion taking place on the generator side, as well as in the power grid side.
\end{abstract}

Keywords: grid connection, harmonic distortion, power electronics and converters, wind energy conversion systems, wind power, wind technology, wind turbines output voltage rises smoothly and a successful startup occurs.

Using power electronic in the various electrical architectures can increase performance and reduces the size and cost of the system. However, electronic converter may cause a degradation of power quality.

The aim of this work is to discuss circuit topologies adopted in wind turbines and its impact on the harmonic flux at the grid side converter and at the machine side. The paper also discusses how to mitigate harmonic distortions in the point of connection to the grid in order to achieve regulatory goals.

\section{Harmonics}

Several static converter topologies are applied to wind energy processing solutions. They are used to the regulation of power flow too. All power electronic converters generate harmonic currents, which will be injected into the utility grid, causing distortion of the utility voltage waveform. Interestingly enough, the technology that allows for more efficient control of electrical energy, switch-mode power conversion technology, is also responsible for a negative impact on power quality.

Regulatory standards for utility system are critical to maintaining the quality of ac power distribution

Corresponding author:

Email:walterdcsan@terra.com.br 
systems. Different measurement considerations and methodologies are used for determining harmonics compliance. Total Harmonic Distortion is an important index widely used in defining the level of harmonic content in electrical facilities. The total harmonic distortion quantifies the thermal effect of all the harmonics. It is the ratio of the rms value of all the harmonics to the fundamental (IEC 61000-2-2).

Harmonics distort the sine wave which becomes apparent when a distorted current or voltage waveform is mathematically analyzed. Through Fourier analysis, an arbitrary periodic function can be divided into a number of sine waves. A non-sinusoidal signal can be decomposed in a sum of some of its multiple in frequency called harmonics. A distorted current or voltage waveform consists of the fundamental frequency and harmonics.

Most harmonic analysis algorithms are based on FFT to obtain the voltage and current frequency spectrum from discrete time samples. FFT is a very efficient algorithm for evaluating Fourier transform. This algorithm becomes considerably more efficient when a large number of data in a discrete sequence need to be transformed into frequency domain.

It is the objective of the electric utility to supply its customers with a sinusoidal voltage of fairly constant magnitude. The generators that produce the electric power must generate a very close approximation to a sinusoidal signal. Grid connected wind turbines are equipped with power converter systems that produce besides the fundamental signal also the harmonic signal.

Power electronic converters in wind energy systems generate harmonic currents and harmonic voltages, which are injected into power system. Harmonic filters reduce distortion by diverting harmonic currents in low impedance paths. These filters can be either active or passive in nature. Passive filters use passive components in their design. They are considered passive because they do not use any active components like semiconductors. Modern active filters are superior in filtering performance, smaller in physical size, and more flexible in application, compared to traditional passive filters using capacitors, inductors and/or resistors. Active filters use sophisticated electronics and power IGBTs to inject equal and opposite harmonics onto the power system to cancel those generated by converters.

Different topologies of the interfacing converter can be used in wind energy conversion to minimize the current harmonic content. Most of the topologies without isolation have an intermediate DC link. It means that on the generator side there is a rectifier while on the grid side is placed an inverter. Some low pass filter can be added to the inverter to fulfill standard requirements. The overall performance of an interface converter is highly affected by the properties of the combination of the generator side and grid side converter.

\section{Electronic Converters}

Electronic converters can be used to convert power supplies from one voltage and frequency to another. A common example is the system that first converts the alternating current (AC) to direct current (DC) and then returns the $\mathrm{DC}$ back to $\mathrm{AC}$. A power electronic device for converting alternating current to direct current is the rectifier. A power electronic device that converts direct current to alternating current is called inverter. The conversion is performed with semiconductor switching devices such as diodes and transistors.

Variable speed wind turbines have some advantages over fixed generation speed, but in this case, the frequency is variable. For this reason, it is necessary to rectify the AC signal coming from the synchronous generator and operate an inverter to synchronize its frequency, phase and amplitude with the utility. The inverter synthesizes an alternating current sine wave from the direct current voltage by the switching frequency. The PWM drives the gates of the power transistors in the inverter. Control is by a voltage source PWM inverter that uses IGBTs for power transistors. The IGBTs are configured in a full H-bridge with freewheeling diodes. Figure 1 shows a three-phase rectifier topology, a DC link and a frequency inverter. The freewheeling diodes are not shown in the Figure 1.

The ability to produce near sinusoidal waveforms around the fundamental frequency is dictated by the modulation technique controlling when the power transistors are on and off. The topology shown in Figure 1 is responsible for keeping the frequency at a fixed value. A fixed frequency output waveform is generated by the inverter to synchronize with the utility. For three-phase SPWM, three modulating signals that are 120 degrees out of phase with one another are used in order to produce out of phase voltages.

The rectifier used in Figure 1 is a simple diode bridge rectifier with capacitor voltage filter. This type of rectifier inherently draws non-sinusoidal current from the generator.

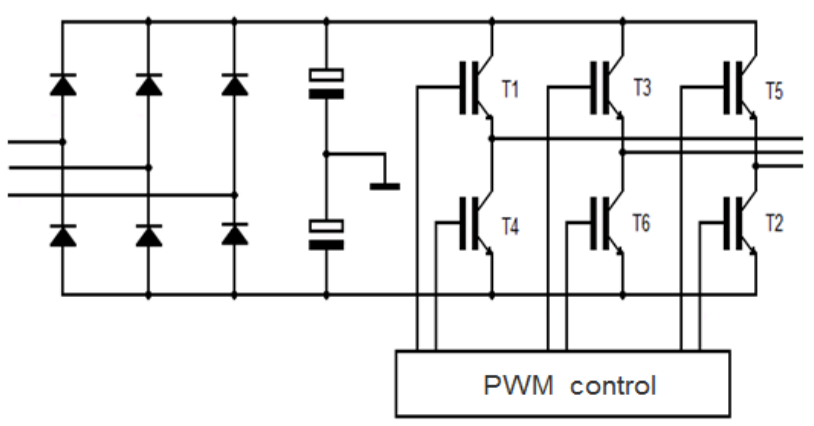

Fig. $1 \mathrm{AC}$ to $\mathrm{AC}$ converter topology 
There is a new topology called active three-phase rectifier that shape the three-phase input current to be sinusoidal and to be in phase with the generator output voltage. In this new topology, also called back-to-back PWM-VSI, the diodes are replaced by six controlled switches to shape the input current. The advantage of this new topology is to reduce alternating current harmonic content and improve power factor to generator side. This topology is shown in Figure 2.

The capacitor decoupling between the grid inverter and the generator inverter offers separate control of the two inverters, allowing compensation of asymmetry both on the generator side and on the grid side, independently [1].

Figure 3 shows the harmonic spectrum of a six pulse diode bridge rectifier. The spectrum is the distribution of the amplitudes of the various harmonics as a function of their harmonic number, often illustrated in the form of a histogram. The amplitude of a harmonic is often expressed with respect to that of the fundamental. In the example of Figure 3, the fifth harmonic current has a magnitude close to $50 \%$ over the value of the amplitude of the fundamental current. It is shown that as the order of harmonic increases, the current amplitude decreases.

The amplitude of the harmonics may vary depending on the value of the capacitance in DC link and the power being transferred through the rectifier. Also, the value of inductance that exists between the rectifier and the source influences the amplitude of the harmonics.

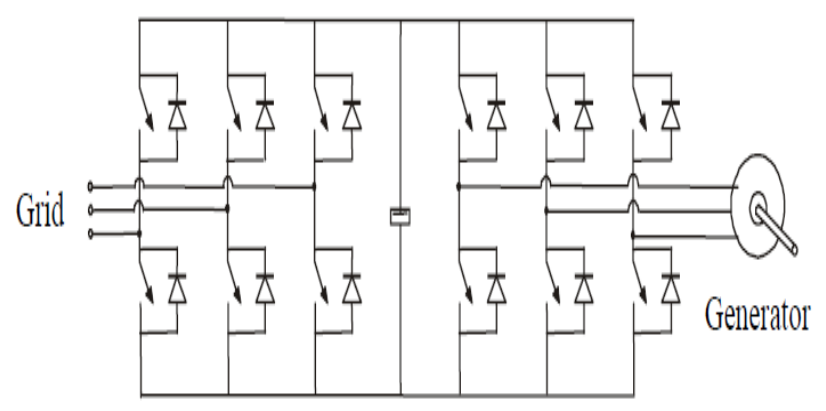

Fig. 2 The back-to-back PWM-VSI topology

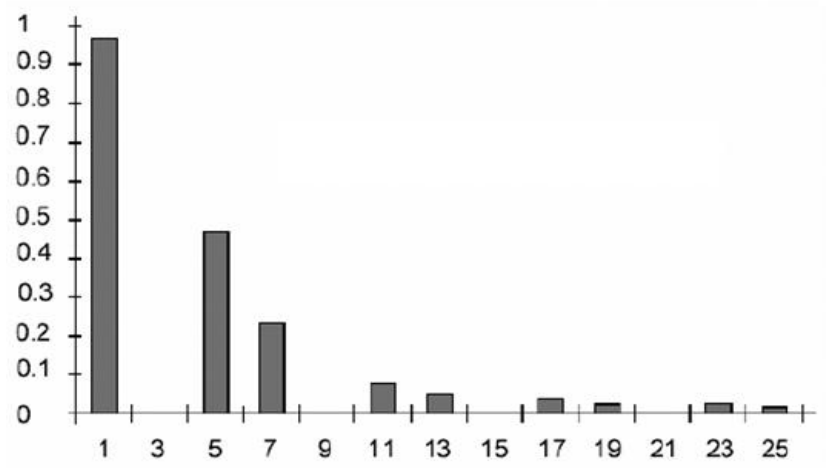

Fig. 3 Harmonic spectrum of a six pulse diode rectifier
The main effects of current harmonics within the armature winding of the generator are additional losses in the stator and in the rotor (copper and iron), and pulsating mechanical torque.

This causes a reduced efficiency and mechanical fatigue due to vibrations. Harmonics increase the rms value of the current for an equal active power generated. It is relatively common practice to "derate" (reduce the output of) generators when supplying nonlinear loads to minimize the effects of harmonic heating. Many of these problems can be resolved, however, using low pass filters at the input of the rectifier.

The system can use active IGBT rectifier in place of conventional diode rectifier. An active rectifier by its construction produces extremely low levels of harmonics. This ensures a total harmonic distortion of less than $5 \%$.

The last stage of the topology shown in Figure 1 represents the frequency inverter. The DC to AC power conversion is the result of power switching devices, which are commonly fully controllable semiconductor power switches like IGBT's. The output waveforms are therefore made up of discrete values, producing fast transitions rather than smooth ones. The ability to produce near sinusoidal waveforms around the fundamental frequency is dictated by the modulation technique controlling when the power switches are on and off. Modulation technique commonly used includes the SPWM technique. Three-phase inverter is used in applications that require sinusoidal voltage. Figure 4 shows an example of a sine wave generated by PWM technique. Three equal waveforms are produced but are phase shifted by 120 degrees.

The PWM waveform has harmonics of several orders in the voltage waveform. The other two phases are identically generated but 120 degrees apart in phase. The line to line voltage will not have any triplen harmonics. PWM techniques produce an AC output waveform from a DC source.

Functions of inverters for wind energy systems are power conversion from variable DC voltage into fixed $\mathrm{AC}$ voltage and frequency, and output power quality assurance with low total harmonic distortion.

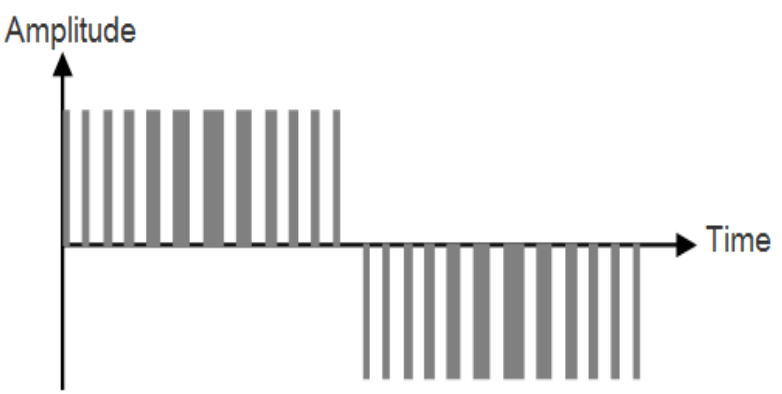

Fig. 4 PWM sine wave 

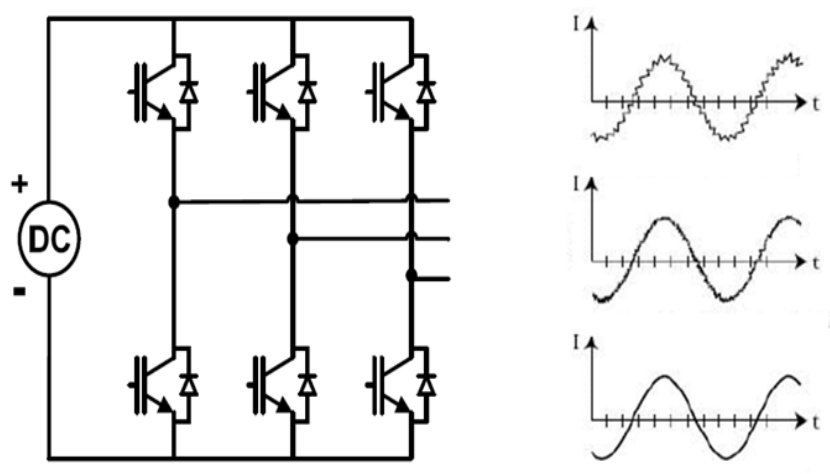

Fig. 5 The effect of switching frequency in the sine wave

The frequency is controlled by controlling the period of the PWM and that is built up with a microprocessor system and synchronized with the utility frequency. The rms value of output voltage can be controlled by varying the width of the pulse. A little longer pulse width will result in a little higher rms output voltage.

The harmonic content at the inverter output has to be effective reduced to admissible values. By controlling the switches to produce PWM, and filtering the output, a nearly sinusoidal line current waveform is obtained. Different output filter topologies are commonly used to interface inverter to the grid, namely the L, LC and the LCL filter. The use of the filter coupling the inverter to the grid reduces the high frequency pollution of the grid that can disturb electric system. The harmonic attenuation with using filter permits the use of a lower switching frequency to obtain harmonic limits, increasing efficiency.

Figure 5 shows the topology required for the power stage of a three-phase inverter and different output waveforms. Different modulation frequencies were used to generate the waveforms shown in Figure 5. In this Figure, the first waveform has a large ripple. In the second waveform, the switching frequency increased and there was a decrease in the ripple. In the third waveform, the switching frequency is higher and the ripple is no longer noticed. In order to generate more precise sinusoidal AC current waveforms and keeping the size of the LC filter small, high modulation frequencies can be used.

\section{Filters}

A sinusoidal pulse width modulation is shown in Figure $6 \mathrm{a}$ and a sinusoidal waveform adapted to connect with the grid can be seen in Figure 6b. Those waveforms were acquired with an oscilloscope. The PWM waveform shown in Figure 6a was filtered before the connection with the grid, in other words, the second waveform, Figure $6 \mathrm{~b}$, was originated by the first one, Figure 6a.

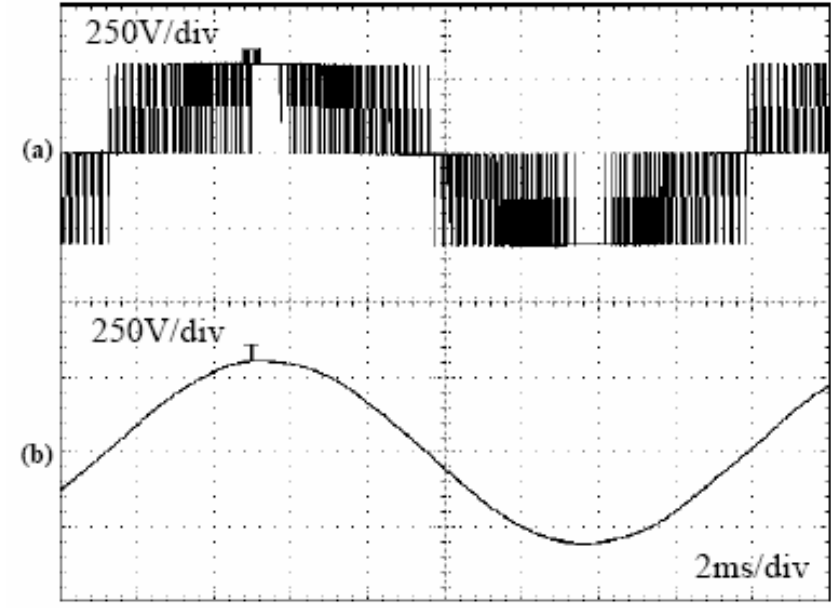

Fig. 6 Sinusoidal pulse width modulation (a) and sinusoidal filtered voltage (b)

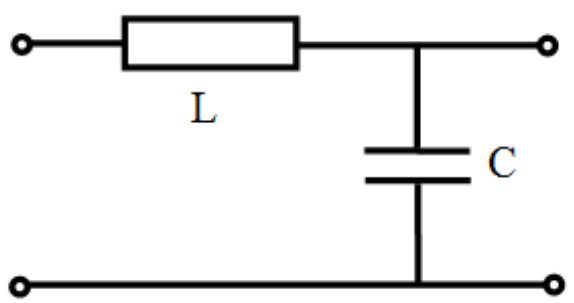

Fig. 7 LC-type low-pass filter

In accordance with Figure 6, the voltage waveform modulated through the frequency inverter is not adapted to connect with the grid. As a result, a series inductor is placed between the grid and the inverter in order to permit the instantaneous differences of voltage between the both sides. This inductor also dampens the sudden current variations caused by that instantaneous voltage differences. In addition to the inductor, is placed a capacitor to storage energy and to control the current flux to the electrical system. The capacitor effect is to attenuate any suddenly variation of voltage waveform.

The emission of harmonic and interharmonic currents from wind turbines with directly connected induction generators has been expected to be negligible in service. Wind turbines connected to the grid through power converters however emit harmonic and/or interharmonic currents and contribute to the voltage distortion. Inverters based on new technologies have a limited emission of harmonics at lower frequencies compared to the converters used in the first generation of variable speed wind turbines. Instead they produce interharmonics at higher frequencies which are easier to filter than at lower frequencies [2].

An LC filter is used to filter the frequencies of high order generated by the inverter. Figure 7 shows an LCtype low-pass filter usually employed to eliminate the switching frequency component of output harmonics. 
A low pass filter only allows low frequency signals from zero Hertz to its cut-off frequency to pass while blocking those any higher. In other words, the filter practically maintains the amplitude of the fundamental voltage component generated by the inverter. However, it attenuates the amplitude in high frequencies.

Depending on the characteristic of the grid, the harmonics can be filtered through the leakage inductance of the transformer and the intrinsic capacitance of the cables. An alternative to the filter previously described is the use of a shunt LC filter tuned in the switching frequency. The advantage of this solution is that this filter would need to be sized only for the rms value of the harmonic current [3].

\section{Power Quality Regulation}

The energy processing through electronic converters adds advantages to the whole system, but it affects the power quality. This does not necessarily affect the operation of the electrical system. The important thing is that the waveform parameters must be in compliance with the indexes recommended by the energy regulatory authority.

The Brazilian Electricity Regulatory Agency determines, through indices defined by resolutions, when a voltage waveform is in accordance with the prescriptions for a good operation of the grid. Those power quality indices can be found in the Distribution Procedures of Electric Energy in the National Electrical System [4] and in the Management of Performance Indices of Basic System and its Components [5] International standards can be used as reference when national standards or recommendations do not try a specific problem. A recommendation used internationally is the "Recommended Practices and Requirements for Harmonic Control in Electrical Power Systems" [6]. This recommendation defines maximum values for each harmonic voltage in percentage of the fundamental voltage. The values of the harmonic currents are defined too. The acceptable value for the voltage and current harmonics depends on the system characteristics. An additional recommendation used specifically in wind turbines is the "European Standard for Testing of Wind Turbines" [7]. In this recommendation is defining a set of requirements to ensure good power quality in the connection of a wind turbine system with the power grid.

\section{Wind Turbine Grid Connection}

There are different technologies to carry out the connection between the wind generator and the electric system. Each technology seeks to adapt to the conditions of variation in wind speed, the power available on the shaft, and the requirements for constant frequency and voltage in the power output. Fixed speed wind turbines cannot use the full potential of wind energy and therefore are giving way to wind turbines with variable speed control [8].

The asynchronous generators, also called induction generators, are used when the turbine speed will be maintained constant. Figure 8 shows a schematic diagram of a wind turbine using an induction generator. This system has a simple construction, low cost, low maintenance and dispenses of synchronism devices. There are two basic needs in this system: thyristors are used to promote a soft starter providing the attenuation of the high starting currents, and the requirement of reactive power to create a magnetic flux necessary to operate the induction generator. This reactive power is usually supplied through capacitor banks, so avoiding the low power factor system. The electronic converter with thyiristors is used in the starting and stopping of the turbine, remaining inactive during steady state operation. This electronic converter is disconnected through a bypass during steady state operation. Harmonics are generated during both the starting and stopping operation and that can affect the system operation.

The turbine speed can be kept constant by controlling the pitch angle. Another way to maintain the speed constant is through the special construction of the blade so that it reaches the stall condition. Some wind turbine systems classified as asynchronous generators type use two generators with different number of poles or a generator with two windings in the stator that permit the operation of the system in two different speeds.

A second system used is the electric generator with wound rotor, also called the doubly fed asynchronous generator. In this case, the turbine rotor operates with variable speed set to the real situation of the wind speed. The stator winding is directly connected to the grid while the rotor winding is connected to an electronic converter and this is connected to the grid. Figure 9 shows a schematic diagram of a wind turbine using a doubly fed asynchronous generator.

In this system, slip control of the asynchronous machine allows the rotor to vary its speed without varying the frequency of the voltage waveform in the stator. The slip control is done through an electronic converter that changes the slope of the torque curve of the generator. The transformer shown in Figure 9 is required to adjust the level of the output voltage of the converter with the voltage level of the stator.

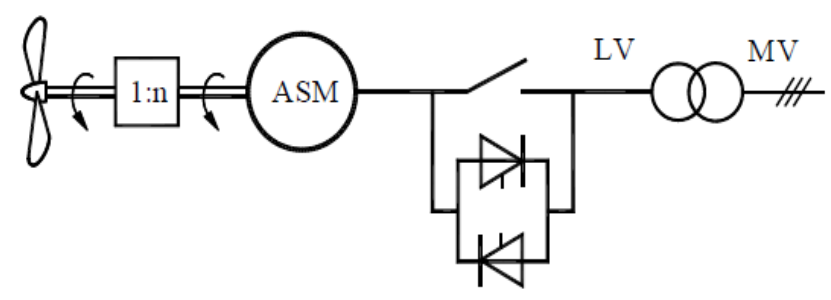

Fig. 8 Wind turbine with asynchronous generator 


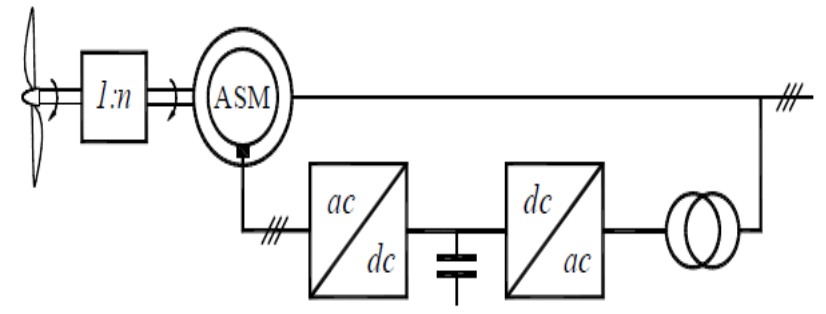

Fig. 9 Wind turbine with doubly fed asynchronous generator

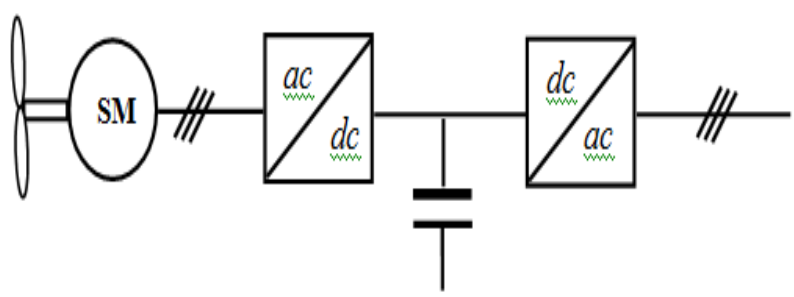

Fig. 10 Wind turbine with synchronous generator

The electronic converter operates in steady state, so harmonics are continually generated. However, as the largest portion of power goes directly to the grid by the stator, a smaller proportion of harmonics is generated. The doubly fed asynchronous generator requires more maintenance because it has collector rings. These collector rings are used to connect the rotor winding to the external circuit.

Another system that allows using variable speed is the one that uses the synchronous generator. In this system, the rotor operates at a variable speed adjusted to the actual situation of wind speed. The frequency generated depends on the wind turbine rotation. Therefore, the generated voltage must be rectified and then to pass for a frequency inverter. The voltage and frequency are adjusted to values of the grid through a frequency converter. Figure 10 shows a schematic diagram of a wind turbine using a synchronous generator. An LC low-pass filter or a shunt filter is used at the converter output.

All power produced by the synchronous generator passes through the electronic converter while only a small portion of the energy produced by the doubly fed asynchronous generator goes through its electronic converter. Therefore, the wind turbine with synchronous generator requires a larger filter for harmonic attenuation.

Currently, there are permanent magnet synchronous generators that require no gearbox (speed amplifiers) because they have a high number of poles. In this case, the generator is directly driven by the rotor of the wind turbine. This increases system reliability because the gearbox is one of the points of failure. The drawback of this type of generator is its large diameter and weight. The increase in weight of the permanent magnet generator is partially compensated because there is no need for the multiplier making the system more compact.

\section{Conclusions}

The availability of electric power within acceptable parameters of power quality is essential to modern society. Many modern facilities are sensitive to poor power quality.

In this paper, the authors reviewed the application of electronic converters for conditioning power produced by wind turbines. The concept of harmonic voltage and current was clarified as well as the consequence of waveform distortions in the electrical system. Some standards and recommendations, both national and international, were cited. The basic principle of sinusoidal waveform PWM was discussed. It was verified the necessity of using an LC filter to attenuate the distortion of voltage and current waveform. Several electronic converter topologies used in wind turbines were shown.

The discussion showed that the variable speed wind turbines require the use of frequency converters and these converters cause injection currents with harmonic content at the grid connection point. The fixed speed wind turbines produce harmonics only in the start and end stages of operation. These wind turbines systems do not produce harmonics in steady state.

\section{Abbreviations}

IGBT - insulated gate bipolar transistor.

PWM - pulse width modulation.

SPWM - sinusoidal pulse width modulation.

DFIG - doubly-fed induction generator.

FFT - fast Fourier transform.

VSI - voltage source inverter.

\section{References}

[1] Hansen LH, Helle L, Blaabjerg F, Ritchie E, Munk-Nielsen S, Bindner H, Sørensen P, Bak-Jensen B (2001) Conceptual Survey of Generators and Power Electronics for Wind Turbines. Ris $\emptyset$ National Laboratory, Roskilde, Denmark.

[2] Mittal R, Sandhu KS, Jain DK (2011) Grid Voltage Control of Inverter Interfaced Wind Energy Conversion System (WECS). International Journal of Environmental Science and Development 2(5).

[3] Araújo SV, Antunes FLM, Sahan e A. Engler B (2007) Analysis And Design of a LCL-Filter for a NPC Inverter in Offshore Wind Power Conversion System. Apresentado no $9^{\circ}$ Congresso Brasileiro de Eletrônica de Potência - COBEP 2007, Blumenau, Brasil.

[4] Agência Nacional de Energia Elétrica (2008) Procedimentos de Distribuição de Energia Elétrica no Sistema Elétrico Nacional PRODIST - Módulo 8 - Qualidade da Energia Elétrica. . ANEEL Resolução no 345 .

[5] Operador Nacional do Sistema Elétrico (2008) Gerenciamento dos indicadores de desempenho da rede básica e de seus componentes - submódulo 2.8, ONS.

[6] IEEE Recommended Practices and Requirements for Harmonic Control in Electrical Power Systems, IEEE Standard: 519-1992. 
[7] European Standards (2008) Measurement and Assessment of Power Quality Characteristics of Grid Connected Wind Turbines. EN 61400-21.
[8] dos Reis FS, Alé JAV, Adegas FD, Tonkoski Jr. R, Slan e K. Tan S (2006) Active Shunt Filter for Harmonic Mitigation in Wind Turbines Generators. 37th IEEE Power Electronics Specialists Conference, Jeju, Korea. 